\title{
El hombre que se equivocaba de conversación. A propósito de las notas sobre Wittgenstein de Oets Kolk Bouwsma
}

\author{
ANTONIO VALDECANTOS \\ Universidad Carlos III de Madrid
}

\begin{abstract}
RESUMEN. Las conversaciones con Oets Kolk Bouwsma son una muestra muy instructiva de algunas de las ideas de Wittgenstein en sus últimos años, en particular sobre asuntos morales. A mi parecer, el tema de si la filosofía es una forma de vida y un juego de lenguaje o si, por el contrario, consiste en una quiebra de otras formas de vida y juegos de lenguaje aparece reiteradamente en las conversaciones. Esta cuestión se halla estrechamente relacionada con el lugar de la moral o la ética en el último Wittgenstein. Probablemente, la moral no haya de ser entendida como un juego, sino como cierta forma de ruptura de ciertos tipos de juegos.
\end{abstract}

Abstract. Conversations with Oets Kolk Bouwsma are a highly impressive text for making sense of Wittgenstein's ideas in his last years, especially about moral affairs and the nature of ethics. One of the major topics of these conversations is perhaps whether philosophy is a form of life and a language game or, on the contrary, the crack of other forms of life and language games. This question is narrowly related to the problem of the place of ethics in the second Wittgenstein. Probably, ethics is not to be interpreted as a game, but as a certain kind of crack of certain kinds of games.

\section{I}

Ningún genio llegaría a nada de no contar con seguidores, por lo menos con uno, preferentemente gris, fiel hasta el sacrificio y lleno de arrebatada admiración, alguien que por nada del mundo esté dispuesto a que su trato con el genio caiga en el olvido. Para los mortales ningún dios sería el que es sin su profeta, pero ningún profeta es nada sin testigos, escribanos, turiferarios, apóstoles y otras clases de acompañantes; el profeta, como el genio, necesita de alguien que dé razón de lo que ha visto y oído, y que lo haga de manera autorizada. A Wittgenstein, desde luego, se lo acostumbra a incluir entre los genios y a veces ha sido calificado de profeta. Así lo hizo, por ejemplo, Oets Kolk Bouwsma, quien, según se advertirá en seguida, pertenece al tipo humano sin el cual los genios nunca se habrían manifestado como tales: Wittgenstein, dice Bouwsma, «es lo más cercano a un profeta que yo haya 
visto jamás; un hombre semejante a una torre, que se alza prominente y sin vínculo alguno, sin apoyarse en nadie, sobre sus propios pies». Los dones del profeta son sublimes y suscitan a su alrededor la más irresistible y turbadora de las fascinaciones; el profeta «no teme a ningún otro ser humano, pero el resto de los hombres le temen a él», él se yergue majestuosamente firme, y eso significa que a su alrededor no puede mantenerse nada en pie. Así pensaba, por lo menos, el bueno de Bouwsma: «No hay nadie a quien le deba tanto, nadie al cual haya escuchado como le escuché a él, nadie a quien haya temido, nadie que fuese mi legítimo juez, mi superior, tan claramente como él lo era. ¡Es horrible trabajar bajo la mirada y el escrutinio de ojos tan penetrantes, tan clarividentes, que saben discernir entre la basura y el oro!»

No está escrito que la figura del genio vaya a seguir existiendo mientras perdure la especie humana; es más: seguramente el genio tiene sus días contados y pocas expectativas de resurrección. La improbabilidad de que vuelvan a darse genios se debe a gran número de factores, aunque el principal es, sin duda, la creciente escasez de personas como Bouwsma. Hasta hace cierto tiempo, a los europeos y los americanos cultos se los educaba no para emular a Wittgenstein - esos advenimientos son cosa de los dioses, no de los planes de estudios-, pero sí para asemejarse a Bouwsma. Por eso surgían individuos geniales cada cierto tiempo, en realidad cada muy poco. Hoy día, por el contrario, cualquiera se avergonzaría de ser el testigo de un genio; eso equivaldría a no haber entendido las condiciones sociales, psicológicas, económicas y demás del personaje en cuestión, a haber olvidado el contexto en que el presunto genio se mueve, y a no tener en cuenta nada de lo que se aprendió en el colegio. Tomar a alguien como un genio sería no haberse enterado de en qué mundo se vive y echar a perder toda una educación primorosamente administrada. Mucho tardará en nacer alguien como Wittgenstein, si es que nace, pero antes tendrían que haber venido al mundo muchas gentes como Bouwsma.

Los profetas y los apóstoles han tenido siempre sus propias señas iconográficas, netamente distintas entre sí. Véase, si no, a nuestros dos personajes. Hay una fotografía tomada por Norman Malcolm en 1949 en la que aparece Wittgenstein con una blusa de cuadros un poco basta; parece el retrato de un hombre de unos treinta y tantos años, cuarenta como mucho, no el de un sexagenario herido de muerte. La imagen contrasta con la de Oets Kolk Bouwsma en torno a 1950 (ambas se recogen en la edición castellana de estas Conversaciones, competentemente traducidas y eruditísimamente anotadas por Miguel Ángel Quintana Paz) *; Bouwsma es diez años más joven que Wittgenstein - tendrá unos cincuenta en el momento de la foto-y su aspecto resulta muy saludable, pero todo el mundo diría que es por lo menos

* Ludwig Wittgenstein y Oets Kolk Bouwsma, Últimas conversaciones, prefacio y apéndice de J. L. Craft y R. E. Hustwit, introducción, traducción y anotaciones de M. Á. Quintana Paz, Salamanca, Sígueme, 2004, 190 pp. 
una generación mayor que Wittgenstein, un probo funcionario cercano a la jubilación, o quizás un benefactor patricio de esos que hay siempre en las universidades de los Estados Unidos. Se trata de un profesor considerablemente exitoso, un hombre cuyas ocupaciones son, por ejemplo, pronunciar las Conferencias John Locke en Oxford, o preparar su contribución al volumen sobre G. E. Moore de la célebre «Library of Living Philosophers», dirigida por Paul Schilpp (y ya veremos los juicios de Wittgenstein sobre esa colección, y sobre lo que el libro dice de Moore). En la profesión filosófica se puede triunfar y está claro qué constituye un triunfo y qué no, mientras que la filosofía a secas - esa de cuyo estudio se ocupa la filosofía profesional- es más bien el resultado de ciertos fracasos memorables, y casi siempre de fracasos profesionales. De Bouwsma puede decirse sin temor a errar que es todo un profesional de la filosofía, algo que Wittgenstein sólo logró de manera desgarrada, intermitente y seguramente defectuosa.

Conviene, antes de pasar más adelante, advertir sobre una notable ironía de estas conversaciones. Merece la pena señalarla, aunque no es, ni muchísimo menos, un caso infrecuente. Por regla general, quienes lean este texto sabrán algo de Wittgenstein antes de ponerse a leerlo, y muchos de esos lectores habrán leído alguna obra o algún trozo del autor, o conocerán de oídas ciertas obras y ciertos trozos pertenecientes a la última etapa de su vida y de su pensamiento, una etapa que Bouwsma conoció directamente, desde luego, pero de manera mucho más pobre que cualquier mediano conocedor de Wittgenstein hoy día. En realidad, muy poco de su profeta había podido leer el apóstol, aparte del Tractatus, esa obra publicada en 1921 y con cuya autoría el Wittgenstein de 1949 sólo se identificaba de manera paradójica y agónica. Una ironía del conocimiento directo (a menudo el más precario de todos) consiste en que muchos estudiantes de segundo curso saben hoy más sobre Wittgenstein de lo que sabía Bouwsma. La principal desdicha de quienes siguen incondicionalmente a los gigantes es que nadie puede darles garantías de que vayan a saber de su gigante favorito más y mejor que una legión de enanos de épocas posteriores, enanos para quienes el personaje en cuestión no será más que un objeto cultural entre otros muchos, y a veces un objeto no especialmente apreciado. Aquel para quien más valor tienen las cosas -o las personas - no siempre es quien mejor sabe por qué son valiosas.

Según la ortodoxia de la epistemología moderna, todo conocimiento se funda en última instancia en cierto saber directo, inmediato y familiar; gracias a ello es como puede conocerse lo difícil, lo confuso, lo lejano y lo incierto. La validez del conocer proviene, según esta doctrina, del poder reducir lo complejo a lo simple: aquello de lo que se habla de oídas, por construcción o por descripción, a lo que puede verse y tocarse con los propios ojos o las propias manos. $Y$ con el lenguaje ocurrirá lo mismo que con el conocimiento: las palabras tienen sentido porque algunas se refieren directamente a las cosas. Esta tesis o familia de tesis ha sido objeto de críticas despiadadas en la cultura 
contemporánea, aunque tiene defensores muy vehementes (y pesadísimos de leer, todo sea dicho) en la filosofía académica angloparlante. Quizá haya campos de la vida humana donde las palabras se refieran directamente a las cosas y lo familiar esté en la base de todo lo demás, pero a poco que uno salga de actividades triviales y de modos de vida primitivos ocurre justo todo lo contrario: lo más familiar e inmediato es lo más difícil de conocer y de designar con propiedad, y exige rodeos larguísimos por territorios extraños, muy poco o nada familiares. Que un vaso esté lleno de agua o no lo esté parece cosa muy fácil de juzgar, pero hay que saber muchísimas cosas más para tener claro que algo es un vaso de agua. Sin ir más lejos, las personas de cultura urbana - y casi todas las demás, en caso de que las haya- no tendríamos concepto ninguno de algo tan sencillo como el agua si no lo tuviéramos también de algo tan extravagante como el grifo, ese retorcido objeto siderúrgico para cuya designación hay que servirse de una rebuscadísima metáfora mitológica. Después afirmaremos, sin duda ninguna, que el concepto del agua no supone el concepto del grifo, pero esta afirmación (cierta al pie de la letra) es francamente alambicada y requiere transportarse a tribus primitivas, arroyos bucólicos y mundos preindustriales, algo sólo asequible a quien esté un poco familiarizado con la etnología, la novela pastoril y la historia social, que son tres productos culturales más bien sofisticados.

La lectura de los autores clásicos, y en general toda lectura, se parece más a los grifos que a los manantiales. De ordinario, el conocimiento directo que se tiene de cierta persona es muy poco relevante para leer sus escritos de manera fecunda. Leer bien no consiste en aproximarse todo lo posible a lo que debía de ser el contexto más próximo y familiar de la obra; si así fuera, los mejores exégetas serían los amigos del autor, sus vecinos o sus parientes. En realidad, escribir para manifestar la identidad propia es una ocurrencia un poco peregrina; salvo los narcisistas y los adolescentes, se escribe suponiendo que, si lo escrito llega a perdurar, será objeto de interpretaciones que uno no puede llegar a imaginarse. Aquello caerá en manos de gentes imprevisibles que harán cosas muy extrañas con el texto, cosas que uno no entendería o que repudiaría con indignación; esto es lo que cualquier escritor debería pensar al meditar sobre la posteridad. Escribir no es preservar la identidad propia - o lo que uno cree que es esa identidad - a lo largo de mucho tiempo, sino exponerse a que a uno se le atribuyan identidades advenedizas seguramente inverosímiles. Pero los lectores del tipo de Bouwsma quisieran ser los intérpretes más autorizados del genio al que conocieron. Hay una terrible ironía en todo esto, porque a menudo ese lector autorizado es uno de tantos, o incluso no es nadie, al lado de alguien que haya leído, por ejemplo, textos inéditos de los que el conocedor directo no tenía ninguna noticia. Para un señor que ha leído un artículo de enciclopedia o una página web, quizá el clásico correspondiente no significa nada especialmente valioso, pero eso no le impide saber más de él que lo que sabe el apóstol. 
Sorprende que el don del profeta consista, según Bouwsma, en distinguir la basura del oro, distinción que cualquiera puede hacer si no tiene las facultades estimativas totalmente atrofiadas. Pero a lo que se refiere Bouwsma es sin duda a otra cosa: a la capacidad de descubrir que hay oro (o basura) allí donde a todo el mundo le pasa inadvertido y, en particular, a la facultad de mostrar que ciertas cosas hasta entonces tenidas por basura son oro y, lo que resulta más temible, también a la inversa. Cuando el profeta dictamina $\ll_{i}$ Eso no es más que basura!», cualquier testimonio en contra queda anulado y se vuelve ridículo, casi pasa a ser igualmente escoria. Importa mucho esta imagen de Wittgenstein como un juez iracundo y oracular, alguien que de manera inapelable puede hacer que se vuelva blanco lo que todo el mundo había tenido hasta entonces por negro. Quizá la filosofía es el arte de mostrar que algunas de las cosas denominadas basura son oro y que muchas de las consideradas oro son propiamente basura, con el añadido de que esto ocurre contra toda previsión y también contra las más acariciadas conveniencias. Pero resulta llamativo porque algunas de las reflexiones de Wittgenstein sobre cuestiones morales versan precisamente sobre lo que podría llamarse la imposibilidad de juzgar, o por lo menos de juzgar en un sentido enfáticamente moral. El Tractatus había afirmado que nada verdaderamente «ético» podía ser dicho nunca y que, si llegaba a decirse con sentido, eso ya era señal de que no es tan ético como se creía. Más o menos, como si alguien emplea las palabras «oro» y «basura» en un sentido pretendidamente valorativo; lo que quiere decir no puede decirlo, tiene que callar. Salvo que se refiera al oro que aparece en el sistema periódico de los elementos y a la basura de la que se ocupa el sistema municipal de recogida de desechos; de esto sí que cabe hablar, y mucho, aunque antes haya que quitarle a lo que se dice todo valor en cualquier sentido valioso: el valor no forma parte de ningún sistema. Podemos, pues, juzgar sobre si esto es oro o no lo es en el sentido físico o químico de la expresión, que es lo único dotado propiamente de sentido, pero no podemos decir de algo, físicamente degradado hasta parecer basura, que es propiamente oro en un sentido peculiar y que ese sentido es el que de verdad interesa. Si podemos hablar del valor de las cosas, entonces lo hablado no tiene ningún valor.

Todo esto, sin embargo, son ideas del Wittgenstein de 1921 y de antes, no del que conversa con Bouwsma en Ítaca (Nueva York) en 1949. El Wittgenstein de sus últimos tiempos ha variado drásticamente de filosofía, y no admite apenas nada de lo que había escrito veinticinco o treinta años antes. Este filósofo, que es el que Bouwsma conoció sin saber exactamente a quién conocía, ya no cree que la ética, la estética y la religión sean imposibles por no admitir proposiciones que de verdad sean tales, es decir, pinturas o figuras de los hechos. Él ya no sostiene que hablar con sentido consista en repre- 
sentar o pintar hechos; las palabras no tienen que ceñirse a las cosas, sino ajustarse a las reglas de juego del hablar, esto es, a las reglas de los muchos juegos a los que se juega mientras se está hablando, a las reglas del contar chistes, del representar papeles, del dar clases o del rezar. Wittgenstein dejó de mencionar «lo ético» cuando cambió de concepción del lenguaje, pero eso no quiere decir que dejara de atormentarse con ello. Más de una vez se refirió al juzgar como algo que sólo podía llevar a cabo Dios, un Dios en el que Wittgenstein no podía creer precisamente porque no creía que fuese a juzgarlo a él: «no creo que vaya a venir a juzgarme», dejó escrito en las Vermischte Bemerkungen, «porque eso no me dice nada, y sólo podría decirme algo si yo viviera de modo muy distinto». Ni Dios ni nadie podría ser un juez así, a pesar de lo que imaginase Bouwsma. Según Wittgenstein, lo más que cabe con estos juicios radicales es vivir de tal manera que la creencia en ellos resulte del todo natural. Pero vivir de ese modo implica probablemente no poder decir nada sobre cuál sería el juicio de Dios; quizá implica sólo confiar en que uno merezca un juicio favorable y atemorizarse de que no sea así. Hay cierto modo de vida dentro del cual tiene sentido pensar en un dios que puede juzgarlo a uno y que puede hacerlo en un sentido más profundo del consistente en decir que esto es físicamente oro de tantos quilates o basura de hace tantos días. Dentro de esa forma de vida se acepta esa manera de hablar, y se acepta conforme a ciertas reglas y a ciertos supuestos implícitos - lo que implica determinada actitud de sometimiento, de temor y quizá de pasiva resignación-, y fuera de esa forma de vida no hay, propiamente, nada de lo que hablar. Éstos son los que se llaman juegos de lenguaje religiosos, o como se prefiera llamarlos. Juegos a los que se juega (y entonces ya no hay más que hablar, porque nada puede decirse fuera del juego) o a los que no se juega (y entonces, claro está, ya no hay nada que decir), ésta es la única cuestión.

Pero no todo debía de ser tan sencillo para el Wittgenstein de 1949 que conversaba con su amigo Bouwsma. Así, el 28 de agosto, mientras ambos pasean al lado de cierta pintoresca cascada, se suscita la vieja cuestión de si el deber hacer algo implica el poder hacerlo. Se trata de un venerable problema de la filosofía moral y de la metafísica sobre el que caben dos tipos de respuesta: afirmar que sí, y que no hay propiamente deberes imposibles porque entonces no serían deberes (el mundo sólo consiente mandatos que pueden cumplirse), o bien negarlo y sostener que por un lado van los deberes - unos deberes que no son de este mundo-y por otro los poderes, de modo que el que se ajusten o no es pura coincidencia. Wittgenstein apostilla que la tesis cristiana ortodoxa se asemeja a esto segundo; de lo contrario, no aparecería en el Evangelio la orden «Sed perfectos», que parece de imposible cumplimiento. Pero «posible» tiene dos usos o contextos de uso distintos: en el primero de ellos se dice que no es posible que al olmo le crezcan peras, y esto es asunto de una ley física, que establece que las peras les cre- 
cen sólo a los perales. En el segundo uso se dice, por ejemplo «iNo puedo!» para dar a entender que uno ya no va a seguir intentando hacer algo, lo que sea, el ser perfecto, por ejemplo, o el ser humilde. De manera que el mandato «Sé humilde» no lleva incorporada ninguna ley como la del olmo y las peras, tan sólo obliga a intentar ser humilde; no implica «puedo», sino «puedo intentarlo».

Este trozo de conversación es muy tranquilizador y gratificante. Apoya la creencia común de que lo moral es asunto de propósitos, de intenciones o de intentos y no de efectos o de resultados, una creencia que comparten todos los usuarios del término «moral», salvo cierto número de profesores de filosofía y de economía un poco antipáticos. Pero lo que no resulta tan claro es que Wittgenstein estuviera en condiciones de ser muy simpático al respecto, ni de quedarse muy contento con el uso común. Que las personas intenten ser humildes es como que las riadas intenten superar cierta cota, de $4,67 \mathrm{~m}$., por ejemplo. Puede ser que los animales humanos logren la humildad y que las riadas logren la cota, o que se acerquen aceptablemente, o que, por la oscuridad de los datos, quepan dudas sobre si ha producido el logro. Sin embargo, para poder jugar al juego de la humildad tiene que estar razonablemente claro cuándo las personas son humildes y cuándo no lo son, e incluso cuándo lo son y dejan de serlo las viviendas, los coches, los almuerzos y las inversiones. Ser humilde es haber logrado ser humilde. Cuando decimos de alguien que es humilde y, además, se nos asegura que la persona en cuestión lo ha intentado, entonces decimos con naturalidad que ha triunfado en el intento; esto es lo único que podemos decir sobre intenciones. La humildad es un asunto exterior y muy poco intencional si bien se mira, o por lo menos si se mira wittgensteinianamente.

Hay otro motivo para hacer poco caso de las intenciones. Porque el humilde que lo es sin esfuerzo -y, por tanto, quizá sin la intención consciente y explícita de serlo- no es de peor condición que el humilde esforzado que ha triunfado en sus intentos. Sólo los ascetas, los puritanos y los reprimidos le darán al esforzado un plus de moralidad, aunque debe advertirse que Wittgenstein fue toda su vida un asceta típico, es decir, alguien mortificado por creer que no había alcanzado todo el rigor ascético que podía lograr. La importancia que se ha dado a las intenciones en la historia de la moral se debe sobre todo al supuesto pesimista de que, por lo común, las acciones humanas son algo torcido y malogrado, y que el único lugar donde puede residir la pureza y el bien es en el fuero interno y en las profundidades sagradas de la intención, un lugar inextenso que puede quedar resguardado del mal. Muchos clásicos de la historia de la moral han pensado de manera instintiva, a menudo sin terminar de decirlo del todo, que el paradigma de la acción moral es el que corresponde a intenciones puras que fracasan al exteriorizarse. Si el mundo está caído y torcido, el único lugar del bien es ese límite suyo llamado intención; lo bueno no puede pertenecer al 
mundo, sino en todo caso a determinada forma de mirar al mundo desde fuera. Todo esto se corresponde muy bien con lo que Wittgenstein le contaba a Bouwsma aquella tarde de 1949. Pero la filosofía de Wittgenstein en sus dos últimos decenios de vida —esa de la que Bouwsma no sabía nada porque estaba sin publicar-oponía serios reparos a la idea de que lo moral pertenece a las intenciones.

Para el Wittgenstein maduro (el que suele llamarse «segundo Wittgenstein») nada relevante puede estar en la interioridad de nadie. El lenguaje y la vida mental son cosa de prácticas y de reglas socialmente aprendidas y están distribuidos en ciertos juegos unidos a formas de vida, unos juegos y formas distintos entre sí aunque a veces parecidos como los miembros de una familia. Saber qué significa la palabra «humilde» y pensar en la humildad no son más que el resultado de haber participado con éxito en algunas conversaciones en las que sale esa palabra y palabras parecidas; si uno entiende lo que le dicen y si los demás le admiten a uno con naturalidad aquellas expresiones suyas en las que aparece el término «humilde», entonces ya no hay nada que añadir, ya se tiene todo lo que se necesita para saber cuándo alguien es humilde y cuándo no, y también para dudar razonablemente sobre ello (el juego de la humildad admite dudas y fomenta el discutirlas). La humildad no es más que eso, ya no hay nada más, eso es lo único que se necesita, y entre las cosas que están de más, las intenciones ocupan un lugar muy destacado, quizá el más destacado de todos. La idea que Wittgenstein parece tener de la moral - $\mathrm{y}$ digo parece, porque el asunto no surge nunca de manera explícita - es la de cierto conjunto de juegos de lenguaje en los que son frecuentes ciertas palabras, unas palabras quizá antiguas y prestigiosas pero que, o se las sabe usar (y entonces ya se ha acabado el problema) o no se sabe qué hacer con ellas (y entonces mejor abandonarlas, o esperar a que por sí mismas caigan en desuso). Bien; es bastante probable que lo moral sea para el Wittgenstein que pasea y conversa con Bouwsma algo semejante a eso, y quizá eso sea todo. Pero nadie dice que algo no es más que tal o cual cosa como no sea que tenga o haya tenido algo más en la cabeza. Por regla general, decir de algo que no es más que esto o lo otro constituye una especie de conjuro o de exorcismo, una fórmula para tratar de sacar demonios que están de más y que deben salir cuanto antes.

Resulta, por tanto, que las ideas sobre lo ético del Wittgenstein de madurez se parecen bastante a las del autor del Tractatus. En esta obra se exhortaba a no decir lo que no puede decirse, mientras que el Wittgenstein de sus últimos años lo que sugiere es no hacer lo que no se puede hacer, y lo cierto es que ambas imposibilidades son semejantes; en el primer caso, de lo que no podía hablarse (porque el lenguaje no era más que pintura o, mejor dicho, dibujo) era del valor profundo de las cosas; en el segundo, lo que no puede hacerse (porque el lenguaje no es más que juegos y reglas públicas) es poner de manifiesto el sentido íntimo de las acciones. En el Tractatus cabía hablar 
de valores, pero con tal de que no tuvieran ningún valor; en los años de vejez cabe jugar a la moral, pero con tal de que aquello no sea más que un juego y allí no pasen más cosas que las que pasan en los juegos. «Un principio resulta ético en virtud de sus alrededores», se dice en un momento de estas Conversaciones. Lo que importa está fuera; está en la superficie o mejor en las cercanías, nunca en la interioridad.

III

Sin embargo, Wittgenstein quería exorcizar ciertos demonios, no cabe ninguna duda. Todo esto de las figuras, las pinturas, los juegos y las formas de vida son procedimientos de terapia, maneras de curar malestares muy íntimos y profundamente destructivos, unos malestares que quizá no podrían curarse nunca del todo. Que la moral no sea más que ponerse a jugar es lo que tiene que creer alguien sano y bien dispuesto ante la vida, alguien que ve las cosas en su sitio, que sabe dónde está el sitio de cada cosa y que se ha adaptado cabalmente al entorno. Pero el Wittgenstein que habla con Bouwsma es cualquier cosa menos un hombre integrado en su medio. La filosofía ha sido asunto, casi siempre, de gente inadaptada que quiere saber en qué consiste su desquiciamiento, y la filosofía de Wittgenstein (la primera y la segunda) es un intento de decir: mira, para que no fueras un inadaptado tendrías que creer esto y esto y esto, y entonces estarías bien instalado en el mundo y no te pasarían las cosas que te pasan, a ver si te vas dando cuenta. Lo malo es que el tener una idea clara de aquello en lo que consistiría estar sano o ser feliz no suele servir en absoluto para calmar los rigores de la enfermedad ni de la desdicha, y esto es lo que debía de pasarle a Wittgenstein con su filosofía, al principio y al final. En realidad, la filosofía de Wittgenstein trata de cómo se ve la salud cuando se está enfermo y sin mucha esperanza de cura.

Que Wittgenstein era un inadaptado, e incluso un hombre a menudo atrabiliario y áspero y desde luego no siempre sociable, es cosa sabida por testimonios de todas las épocas de su vida. Sin duda ninguna, Bouwsma está dispuesto a considerar genialidad cualquier extravagancia, cuanto más desabrida mejor, pero hay que reconocer que alguna de las asperezas de Wittgenstein es bien significativa: «Esta tarde, después de la conversación de anoche en casa de Black, Wittgenstein vino a verme», dice Bouwsma. «Yo me había estado sintiendo muy incómodo últimamente, y hete aquí que vino a verme y que iba a estar con él a solas. Bajé por la calle con el fin de encontrarme con él. Y pronto apareció, a la vuelta de la esquina, con su bastón y un modo de caminar muy desganado, agarrotado y, sin embargo, bastante vigoroso. Le saludé y le comenté que parecía ser un buen andarín; curiosamente él se toma estas bromas muy en serio: que no, que él no resultaba ser un buen 
andarín en absoluto, etcétera. Luego se volvió, en seguida, hacia mí, y se puso a explicarme por qué había venido a verme. Quería hablar de nuestro encuentro de la noche anterior. ¿Resultó positivo, había sacado yo algo en claro de todo aquello?» Wittgenstein se acusa constantemente de engreimiento (de nuevo la obsesión de la humildad) y atribuye a esto el que la charla «no fue buena». Bouwsma le pregunta si ese tipo de veladas le hacen perder el sueño y la respuesta de Wittgenstein es del todo inopinada: «No, pero ¿sabe usted?, creo que puedo volverme loco.» Agrega los motivos por los que renunció a la cátedra de Cambridge: quería terminar «su libro» (lo que acabaron siendo las Investigaciones filosóficas) y además no podía soportar que los alumnos lo apreciaran por motivos que para él eran espurios: «la mayoría de ellos se acercan hasta mí sólo porque soy listo; y lo cierto es que soy listo, pero eso no importa. Pues también los funambulistas son listos». Bouwsma reconoce con mal disimulado orgullo que Wittgenstein lo está tomando como confidente y recuerda otra declaración de ese mismo día: «Anteriormente me había comentado que la ciencia o la electrónica son asépticas, y que una charla como la nuestra de anoche también lo era. Pero la filosofía...»

La desazón de Wittgenstein parece deberse a que la conversación de la noche anterior no fue adecuadamente filosófica, y a que no lo fue por ser aséptica, por ser cosa de gente lista, casi cantabrigense o funámbula. Wittgenstein no se queja de que la conversación haya fracasado en el sentido en que normalmente se dice que fracasan las conversaciones, cuando los interlocutores son hostiles, están ofuscados, no tienen nada que decirse o se enredan en malentendidos. No: parece que la conversación fue un desastre - fue uno de esos episodios que le hacen pensar a Wittgenstein que puede volverse loco- porque se atuvo demasiado escrupulosamente a las reglas de cierto tipo de conversaciones. Eso es lo que Wittgenstein no puede soportar: decir lo que se tiene que decir, de la manera adecuada y en el momento oportuno, satisfaciendo las convenciones de un género reconocible como tal. Lo que Wittgenstein no puede soportar es que la filosofía se reduzca a un tema de conversación o, si se quiere, a un juego de lenguaje. No se sabe muy bien lo que podría querer decir que hay reglas para hacer filosofía. Puede haberlas quizá para la historiografía de las ideas o para la presentación ordenada de ciertas cuestiones y problemas - cosas que sí son objeto de conversación, y aun de juegos de lenguaje más solemnes-, y en estos quehaceres se puede brillar como un fellow de Cambridge o como un funambulista, pero eso no es hacer filosofía, a la manera de Wittgenstein. En su encuentro con Bouwsma parece importarle mucho si la conversación de la noche anterior fue provechosa, si se había sacado algo de ella, y no en el sentido utilitario del término, sino quizás en el de si aquello había sido algo más - tan sólo un poco más, si acaso- que una mera conversación. El desasosiego de Wittgenstein es el de alguien que se vuelve a dar cuenta de que en filosofía todo es hablar, 
y nadie mejor que él para saber lo que pasa cuando nos ponemos a hablar, que no es nada muy misterioso ni muy profundo. Hay cosas que habría que decir, pero que quizá no puedan decirse, ni anoche en casa de Max Black ni nunca en ningún otro sitio.

Quizá convenga reparar en un detalle menor de la conversación entre Wittgenstein y Bouswma, no de aquella de la que hablan los dos, sino de aquella entre los dos de la que habla Bouwsma. Cuando el apóstol ha salido al camino del profeta y lo ha visto, le dice el típico cumplido, Vaya un andarín que está hecho usted, doctor Wittgenstein, o algo semejante. Todos sabemos participar en juegos de lenguaje como éste, entre bromas y veras, y todos sabemos lo que es tomarse completamente en serio lo que es sin duda ninguna una declaración frívola, irónica o irrelevante. A veces, estas confusiones ocurren por descuido o por estar uno pensando en otra cosa, pero hay momentos en que suceden por la recalcitrante y tenaz incapacidad de los interlocutores para estar donde tienen que estar y para ajustarse a las circunstancias - a los alrededores-. Y esto es precisamente lo que le pasa a Wittgenstein; está en una sintonía distinta de la de su interlocutor y, cuando oye que es un buen andarín, no responde como se contesta a los cumplidos que lo son medio en broma: se toma lo que oye al pie de la letra, y poco le falta para hacer una disertación sobre las propiedades anatómicas de sus piernas, o algo por el estilo. Wittgenstein es un inadaptado social que no está a gusto en una conversación filosófica porque cree que la filosofía no es materia de conversación y que tampoco es capaz de seguir una conversación trivial porque abomina de la trivialidad. Para poder sacar provecho de lo que enseña su filosofía, tendría que ser capaz de una cosa y de la otra, pero no está claro que Wittgenstein aprovechara nunca su propio pensamiento, ni tampoco que fuese a tener un juicio muy favorable sobre quien sí lo hiciera. En caso de creer en el provecho y en la utilidad, muy bien podría haber acudido al dinero de su familia, la más rica de toda Kakania.

Bouwsma dice que Wittgenstein se tomaba las preguntas completamente en serio y las examinaba hasta sus últimas consecuencias. Lo que suelen hacer las personas normales con las preguntas es tratar de responderlas o, de lo contrario, desecharlas por triviales, por impertinentes o por imposibles. Pero también cabe darles todas las vueltas que se sea capaz de imaginar, trastornarlas, cambiarles el sentido, mezclar unas con otras, mirar qué tiene que pasar para que sean posibles o qué pasa para que no lo sean, engolfarse en la imposibilidad de respuesta (atormentándose por ello o celebrándolo), responder con el silencio y glosar ese silencio igual que se comentan las palabras, curar las heridas que una pregunta puede llegar a infligir o reabrir las corres- 
pondientes cicatrices, renegar del tiempo que se ha gastado con semejantes quehaceres, todo eso son cosas que se hacen con preguntas (o que se dejan de hacer o se abandonan a medias). Alguien podría decir que estas maneras de proceder no son tan disparatadas como a veces se cree y que configuran, a su modo, una práctica o juego peculiar, que es el juego de la filosofía, un juego unido, al igual que los otros, a cierta forma de vida. En verdad, la afirmación de que la filosofía constituye una forma de vida es muy antigua y célebre. Pero cabe oponer, me parece, dos reparos a esta manera de argumentar.

El primero es que, para ser un juego, la filosofía resulta quizá demasiado anómala y desarreglada. Más que como un juego puede verse como un conjunto de quebrantamientos de las reglas de otros juegos: del juego de la ciencia, del de la religión, del de la política, y también del juego constituido por el pensamiento académico. Que este último es una práctica reglada no puede ofrecer ninguna duda; no sólo es un juego, sino un complicado sistema de ritos y ceremonias, tanto más amaneradas quizá cuanto más modernos y antitradicionales sean los jugadores. Sacar de quicio las preguntas y sus respuestas es algo que, como todo, puede hacerse bien y mal, pero lo que no resulta claro es que se parezcan mucho entre sí las formas que hay de hacerlo bien; acaso no se asemejen lo suficiente para que se las pueda llamar del mismo modo sin que el nombre sea un puro enredo y una equivocación.

El segundo es que, como modo de vida, la filosofía no parece funcionar muy satisfactoriamente. Véase, si no, lo que Bouwsma le oye a Wittgenstein de personajes como Russell, Dewey o Whitehead, filósofos que no son precisamente de segunda fila: «Empezó también a hablarme acerca de los libros de Paul Schilpp: ¡son totalmente estúpidos! Nunca había leído ninguno de ellos. Había abierto el dedicado a Moore, había leído lo que cuenta sobre la infancia de Moore: muy bonito, pero también un zapatero tiene infancia, muy bonito.» No debía de saber Wittgenstein - ¡o sí! - que Bouwsma era uno de los colaboradores de ese libro, precisamente. «Dewey: ¿estaba Dewey aún vivo? Sí. No valía la pena que lo estuviese. Russell había sido muy bueno hacía tiempo: había desarrollado una tarea bien dura, y Cambridge le había echado cuando aún era así de bueno; sin embargo le invitó a volver luego, cuando ya era malo.» Lo que vale de Russell vale también de Whitehead: «era muy bueno antes de convertirse en un charlatán». Parece como si los filósofos estuviesen condenados a serlo sólo durante cierto tiempo, quizá en la juventud, y no pudieran ser buenos de por vida. Más que un juego que puede practicarse durante la vida entera y en donde uno aprenda de sus propios errores, aquí resulta que los errores son definitivos y echan a perder el propósito mismo. A la filosofía le falta bastante para ser una forma de vida y tiene que conformarse con unos cuantos episodios, por lo general pocos y breves. Acaso sea ésta una de las razones de las propensiones suicidas de Wittgenstein: para convertir en filosófica la propia vida, lo mejor sería acortarla voluntariamente... 
El profeta cuenta que ha coincidido con Russell hace relativamente poco en Cambridge, en el Club de Ciencia Moral, y que no se dirigieron la palabra: «habían pasado el uno junto al otro, pero sin hablarse: no hubiese servido de nada», apunta Bouwsma. A veces las conversaciones hay que eludirlas, es lo mejor que se puede hacer con ellas. Otras veces, uno cree estar haciendo ciertas cosas con palabras y su creencia resulta disparatada. Creemos ser originales mientras repetimos lugares comunes, divertir mientras causamos compasión o aburrimiento y perdonar mientras ofendemos; y también al revés, también nos llevamos alegrías, a veces memorables. De estas confusiones está hecha cualquier conversación; no siempre que hacemos algo tenemos al mismo tiempo una idea clara sobre qué es eso que hacemos, sobre qué lugar le corresponde en el catálogo de las acciones humanas. Si se le pregunta a alguien qué hace, dirá que está comiendo, o leyendo, o que no está haciendo nada de particular, y se supone que normalmente acertamos en este tipo de descripciones. Pero la vida se complica mucho cuando esas descripciones empiezan a acumular errores. Si uno lancea las aspas de un molino y dice estar atacando a un gigante, lo que se suele afirmar de él es que está loco (y Wittgenstein temía mucho la locura).

Para Wittgenstein, el orden de las cosas consistía sobre todo en hablar y actuar conforme a las reglas de los lenguajes y de las acciones, sin confundir unas con otras y sin creer que se actúa conforme a reglas que en realidad no se están siguiendo. Lo demás es salirse de los límites del juego, de manera parecida a como en sus años de juventud creía que algunas maneras de hablar querían traspasar los límites del mundo. Está empeñado en mostrar que lo que uno cree que hace tiene muy poca importancia: lo que importa es lo que haces de hecho, y eso no eres tú quien lo decide. Cabe equivocarse en muchas cosas, y también equivocarse de conversación. Para darse cuenta de lo que significa el que alguien cumpla con las reglas de un juego de lenguaje es muy bueno, casi es imprescindible, imaginar lo que pasaría si uno cumple con esas reglas creyendo que no lo hace o creyendo que juega a otra cosa. Uno comprende lo que tiene que comprender cuando se da cuenta de que esto último es irrelevante, pero nadie comprendería esto si no se hubiera equivocado alguna vez, porque sin quebrantamiento no habría regla ninguna. La lección de Wittgenstein es que el orden y la salud provienen de no equivocarse de conversación, aunque ese orden saludable es dificílisimo de lograr, es una normalidad demasiado rara, demasiado normal para ser frecuente.

Qué hacía Wittgenstein en sus lecciones, sus conversaciones y sus escritos es sólo materia para un juego, para el complicado juego de leer a Wittgenstein y hablar de lo que se ha leído. En este juego resulta claro que no es Wittgenstein el que manda; mandan unas reglas que muchas veces no se sabe cuáles son y que otras veces no existen, como en todos los juegos de lectura y comentario. Es común en ese juego creer que, si uno hace una bue- 
na jugada, invalidará con ella todas las de los otros jugadores anteriores; el sueño de todo jugador es realizar una jugada como ésa, y parece natural que los conocedores directos de Wittgenstein crean que juegan con ventaja. Pero ya sabemos que eso no es verdad, porque los juegos suelen urdir terribles ironías cada vez que alguien presume de jugar con ventaja. En juegos tan inciertos y escurridizos como éste, uno no conoce casi nunca el valor de su propia jugada. En una ocasión, Ortega sugirió que convenía expresarse con ambigüedad para animar a los estudiosos a resolver enigmas y a emprender investigaciones sobre uno. Es muy difícil imaginarse a Wittgenstein diciendo una cosa así, o pensándola. En realidad, Wittgenstein había leído muy poca filosofía, y no parece que le fascinase mucho lo que pudiera pasar con sus textos en mano ajena. Comentar a Wittgenstein es una actividad casi exclusivamente profesional, y para algunas personas puede llegar a constituir toda una forma de vida. El tenía muchos motivos para creer que de estas ocupaciones de jugadores profesionales no cabía esperar nada muy valioso. Y lo más probable es que esos motivos sean los mismos por los que nada muy valioso puede ser objeto de una profesión, ni de un juego, ni de una forma de vida. Wittgenstein comenzó creyendo que lo ético es inexpresable y acabó sosteniendo que es impracticable. Empezó colocándolo en los límites del mundo y terminó sugiriendo que, de encontrarse en algún sitio, tendría que estar allí donde una práctica deja de ser esa práctica, y se deja de jugar allí donde los juegos se confunden, las reglas se suspenden y las conversaciones se equivocan. 